\title{
First Chinese student in Plymouth as part of dental partnership
}

Following the signing of memoranda of agreement between the University of Plymouth and four institutions in China last year, the first Chinese student to take advantage of one of the partnerships has arrived in Plymouth.

Yan Gao is a Masters student from the School of Stomatology at Capital Medical University in Beijing, where she has studied dentistry for five years and orthodontics for one year. Yan's visit is for six months and she will be working with internationally-

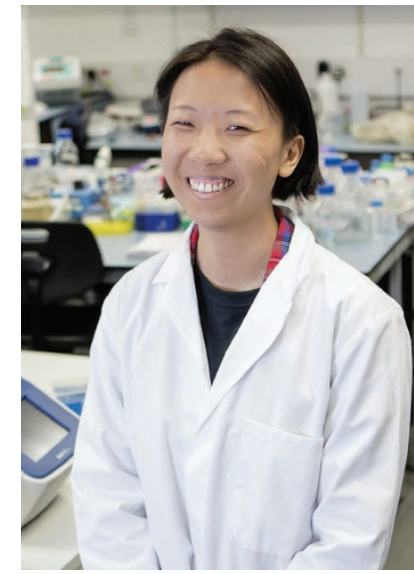
renowned stem cell researcher, Dr Bing $\mathrm{Hu}$.

Their research project will focus on better understanding stem cells and their role in craniofacial tissue and bone regeneration - how they are activated, can prevent damage and accelerate wound healing.

There are two targets for the research: the first is to develop a way to accelerate new bone and tooth ligament formation during tooth movement due to orthodontic treatment (especially in children), to reduce the current significant length of clinical treatment and cost.

The second is to understand the mechanism of bone development deformity in children with Crouzon Syndrome (CS). CS is a rare genetic disorder where soft bones in young children's skulls fuse prematurely (usually there is flexibility to allow for the head and the structures and functions within it to grow). Treatment of CS patients is long, painful and requires multiple plastic surgery and orthodontic operations and therapies. Targeting stem cells in the bone may hold the key to accelerated healing, reducing the painful period for the patient. Very few research groups are working in this area. The team is collaborating with Dr Pauws Erwin from the UCL Institute of Child Health for the project.

Yan said: 'It's great being here in Plymouth and very exciting to be the first student from China to visit as part of these new arrangements. At home I am a research clinician with 60 child and adult patients. While in Plymouth I am looking forward to working with Bing and his colleagues and to learning new technology. Everyone here is so friendly and always offering help in the lab.'

\section{Erratum}

\section{Book Review Br Dent J 2017; 222: 501}

In the original book review the price, page count and ISBN listed for Essentials of Dental Caries, Fourth Edition were incorrect.

The correct price is $£ 29.99$, the correct page count is 216 and the correct ISBN is 9780198738268 .

We apologise for this error and the inconvenience caused. 